OPEN ACCESS

Edited by:

Francesco Moccia,

University of Pavia, Italy

Reviewed by:

Senthilkumar Rajagopal,

Rayalaseema University, India

Yaohui Tang,

Shanghai Jiao Tong University, China

*Correspondence.

Mingyang Zhang

mingyangzhang@suda.edu.cn;

ghost8469@163.com

Luyang Tao

taoluyang@suda.edu.cn

tThese authors have contributed equally to this work

Specialty section:

This article was submitted to

Cellular Neuropathology,

a section of the journal

Frontiers in Cellular Neuroscience

Received: 17 January 2019

Accepted: 15 July 2019

Published: 07 August 2019

Citation:

Shan H, Qiu J, Chang P, Chu Y, Gao C, Wang $H$, Chen G, Luo C, Wang $T$, Chen $X$, Zhang $M$ and Tao $L$ (2019) Exogenous Hydrogen Sulfide

Offers Neuroprotection on Intracerebral Hemorrhage Injury Through Modulating Endogenous $\mathrm{H}_{2} \mathrm{~S}$ Metabolism in Mice.

Front. Cell. Neurosci. 13:349. doi: $10.3389 /$ fncel.2019.00349

\section{Exogenous Hydrogen Sulfide Offers Neuroprotection on Intracerebral Hemorrhage Injury Through Modulating Endogenous $\mathrm{H}_{2} \mathrm{~S}$ Metabolism in Mice}

\author{
Haiyan Shan ${ }^{1,2+}$, Jianping Qiu't, Pan Chang ${ }^{3+}$, Yang Chu', Cheng Gao', \\ Haocheng Wang', Guang Chen', Chengliang Luo', Tao Wang ${ }^{1}$, Xiping Chen', \\ Mingyang Zhang ${ }^{1,4 *}$ and Luyang Tao ${ }^{1 *}$ \\ 1 Institute of Forensic Sciences, Soochow University, Suzhou, China, ${ }^{2}$ Department of Obstetrics and Gynecology, \\ The Affiliated Suzhou Hospital of Nanjing Medical University, Suzhou, China, ${ }^{3}$ Central Laboratory, The Second Affiliated \\ Hospital of Xi'an Medical College, Xi'an, China, ${ }^{4}$ School of Pharmacy, Soochow University, Suzhou, China
}

Hydrogen sulfide $\left(\mathrm{H}_{2} \mathrm{~S}\right)$, an important endogenous signaling molecule, has a significant neuroprotective role in the central nervous system. In this study, we examined the protective effects of exogenous $\mathrm{H}_{2} \mathrm{~S}$ against intracerebral hemorrhage $(\mathrm{ICH})$, as well as its underlying mechanisms. We investigated the effects of exogenous $\mathrm{H}_{2} \mathrm{~S}$ on $\mathrm{ICH}$ using Western blotting, injury volume, measurement of brain edema, propidium iodide (PI) staining, and behavior assessment, respectively. We found that endogenous $\mathrm{H}_{2} \mathrm{~S}$ production was downregulated in the brain after $\mathrm{ICH}$, which is caused by the decrease in cystathionine $\beta$-synthase (CBS) as the predominant cerebral $\mathrm{H}_{2} \mathrm{~S}$-generating enzyme in the brain. Treatment with sodium hydrosulfide (NaHS; an $\mathrm{H}_{2} \mathrm{~S}$ producer) could restore the $\mathrm{H}_{2} \mathrm{~S}$ production and the expression of CBS. NaHS could also attenuate brain edema, injury volume, and neurological deficits in the Morris water maze test after $\mathrm{ICH}$. Western blotting results indicated that $\mathrm{H}_{2} \mathrm{~S}$ pretreatment reversed the increase in caspase 3 cleavage and the decrease in Bcl-2, suppressed the activation of autophagy marker (LC3II and Beclin-1), and maintained the p62 level in injured striatum post-ICH. However, $\mathrm{H}_{2} \mathrm{~S}$ could not restore brain CBS expression and $\mathrm{H}_{2} \mathrm{~S}$ content, reduce brain edema, and improve motor performance and memory function after $\mathrm{ICH}$ through modulating autophagy and apoptosis when pretreated with the CBS inhibitor aminooxyacetic acid (AOAA). We also found that AOAA reduced the endogenous $\mathrm{H}_{2} \mathrm{~S}$ production through inhibiting the enzyme activity of CBS rather than modulating the expression of CBS protein level. These present results indicate that $\mathrm{H}_{2} \mathrm{~S}$ may possess potential therapeutic value in the treatment of brain injury after $\mathrm{ICH}$, and the protective effect of exogenous $\mathrm{H}_{2} \mathrm{~S}$ against $\mathrm{ICH}$ may be not a direct action but an indirect effect through inducing endogenous $\mathrm{H}_{2} \mathrm{~S}$ metabolism responses.

Keywords: hydrogen sulfide, intracerebral hemorrhage, autophagic cell death, apoptosis, mice 


\section{INTRODUCTION}

Intracerebral hemorrhage ( $\mathrm{ICH})$ is the second most common subtype of stroke (up to $15 \%$ of all strokes) leading to high mortality and morbidity throughout the world (van Asch et al., 2010; Kim and Bae, 2017). The post-ICH brain injury can be distinguished into primary brain injury caused by disruption and mechanical deformation of brain tissue due to hematoma growth, and secondary brain injury induced by microglia activation, mitochondrial dysfunction, and neurotransmitter and inflammatory mediator release, which lead to cell death, including apoptosis and autophagy (Bobinger et al., 2018). These cell death pathways lead to the removal of inactivated and damaged cells and also result in neuronal cell damage and poor neurological outcome (Lin et al., 2018). Recent evidence indicates that compensatory response as a strategy offers promising opportunities for each participant to improve brain function following brain injury (Tovar-y-Romo et al., 2016; Rodriguez et al., 2017). To develop a suitable neuroprotective agent, which can enhance the protective pathways to treat hemorrhage stroke, may be regarded as a promising treatment option when transitioned to the clinical setting.

Hydrogen sulfide $\left(\mathrm{H}_{2} \mathrm{~S}\right)$ is most recently found to be a novel gasotransmitter signaling molecule, which can modulate cellular biological function related to health and diseases ( $\mathrm{Li}$ et al., 2011). The effects of $\mathrm{H}_{2} \mathrm{~S}$ have been extensively researched, including the regulation of inflammation, cell death, and cellular metabolism (Gopalakrishnan et al., 2018). Recent basic medical studies and preclinical studies on neurological diseases have demonstrated that treatment with $\mathrm{H}_{2} \mathrm{~S}$ at physiological or pharmacological levels attenuates brain injury (Zhang et al., 2013; Zhang J.Y. et al., 2017). Zhao et al. reported that $\mathrm{H}_{2} \mathrm{~S}$ attenuated NLRP3 inflammasome-mediated neuroinflammation after ICH (Zhao et al., 2017). They also found that supplement with taurine could increase $\mathrm{H}_{2} \mathrm{~S}$ content, enhanced cystathionine $\beta$-synthase (CBS) expression, and effectively mitigated the severity of pathological inflammation after ICH (Zhao et al., 2018). Despite the performance of the protective role of $\mathrm{H}_{2} \mathrm{~S}$ in neuroinflammation after $\mathrm{ICH}$, how $\mathrm{H}_{2} \mathrm{~S}$ regulates cell death including apoptosis and autophagy in ICH remains unclear. Our previous study demonstrated that $\mathrm{H}_{2} \mathrm{~S}$ provided neuroprotection in traumatic brain injury (TBI) via inhibition of autophagy and apoptosis (Zhang et al., 2014). We also found that ICH induced the activation of autophagy, and inhibition of autophagy was recognized as a therapeutic strategy of brain injury after hemorrhage in an ICH model (Shen et al., 2016). Based on the findings mentioned above, a mouse model of ICH was established to evaluate therapeutic efficacy and neuroprotective mechanism of $\mathrm{H}_{2} \mathrm{~S}$ against brain injury.

Obviously, $\mathrm{H}_{2} \mathrm{~S}$ is generated from cysteine by CBS in the brain and regulates different cellular physiological functions such as ion channel and release of neurotransmitters by acting as intracellular signaling molecules (Kamat et al., 2015). Neurological effects of $\mathrm{H}_{2} \mathrm{~S}$ recently were put forward to account for the regulation of circulating sulfide rather than endogenous production (Olson et al., 2008). This was disproved based on recent studies showing that $\mathrm{H}_{2} \mathrm{~S}$ found in the
CNS is more likely to be derived directly from the brain than from the blood (Whiteman et al., 2004; Kim et al., 2011). Moreover, no clear mechanisms of exogenous $\mathrm{H}_{2} \mathrm{~S}$ modulating endogenous $\mathrm{H}_{2} \mathrm{~S}$ pathway were addressed, and biological effects of endogenous $\mathrm{H}_{2} \mathrm{~S}$ synthase inhibitors were not investigated after ICH. In order to elucidate the molecular mechanism of exogenous $\mathrm{H}_{2} \mathrm{~S}$, we also added the endogenous $\mathrm{H}_{2} \mathrm{~S}$ synthase inhibitor to investigate whether exogenous $\mathrm{H}_{2} \mathrm{~S}$ exerts a protective effect against brain injury through endogenous $\mathrm{H}_{2} \mathrm{~S}$ pathway.

\section{MATERIALS AND METHODS}

\section{Animals and Drug Treatments}

Adult male CD1 mice with an average body weight of $23 \mathrm{~g}$ (20$25 \mathrm{~g}$ ) were used in this study. Sodium hydrosulfide (NaHS), an $\mathrm{H}_{2} \mathrm{~S}$ donor, was obtained from Sigma-Aldrich (St. Louis, $\mathrm{MO}$, United States) and dissolved in saline. $\mathrm{O}$-(carboxymethyl) hydroxylamine hemihydrochloride (AOAA), an $\mathrm{H}_{2} \mathrm{~S}$ inhibitor, was obtained from Sigma-Aldrich (St. Louis, MO) and dissolved in saline. For drug time effects assays, NaHS was intraperitoneally (i.p.) injected $30 \mathrm{~min}$ before or $30 \mathrm{~min}, 1,2$, 4, or $6 \mathrm{~h}$ after ICH. For drug dosage effects assays, NaHS $(1,10,25,50$, and $100 \mu \mathrm{mol} / \mathrm{kg}$ ) was i.p. injected $30 \mathrm{~min}$ before ICH. AOAA was i.p. injected $1 \mathrm{~h}$ before ICH. Animals were grouped into sham, ICH, $\mathrm{ICH}+\mathrm{NaHS}$, ICH + AOAA, and ICH + NaHS + AOAA groups. Sham-injured mice received craniotomy and injection with saline without ICH. All the animal procedures were approved by the Institutional Animal Use and Care Committee at Soochow University and conducted in accordance with the guidelines of animal use and care of the National Institutes of Health (NIH) and the ARRIVE (Animal Research: Reporting In Vivo Experiments). All efforts were made to minimize the numbers of animals used and ensure minimal suffering. In all experiments, data were obtained by investigators blinded to study group.

\section{ICH Model}

The ICH model was used as previously described (Wang et al., 2013). The CD1 mice were deeply anesthetized with chloral hydrate ( $4 \%$ solution), and surgery was performed under aseptic conditions and mounted in a stereotaxic system (David Kopf Instruments, Tujunga, CA, United States). The following steps were all performed using aseptic techniques. A midline incision on the scalp exposed the skull without requiring muscle retraction. Craniotomy was performed by handheld trephine and injected with Type IV collagenase $(0.075 \mathrm{U}$ in $500 \mathrm{nl}$ of saline) unilaterally into the left striatum at the following stereotactic coordinates: $1 \mathrm{~mm}$ anterior and $2.0 \mathrm{~mm}$ lateral of the bregma, $3.5 \mathrm{~mm}$ in depth. Collagenase was delivered over $5 \mathrm{~min}$. The needle stayed in place for an additional $5 \mathrm{~min}$ to prevent reflux. The craniotomy was sealed with bone wax, and the scalp was sutured. Mice in the sham group were only subjected to sterile saline injection. The overall mortality rate was $<2 \%$. All mice were allowed to fully recover under observation. Body temperature was maintained at $36.5-37.5^{\circ} \mathrm{C}$ by means of a heating blanket and a lamp throughout the procedure 
from the start of the surgery until the animals recovered from anesthesia. Animals were housed under a 12-h light/dark cycle in a pathogen-free area with free access to water and food. All surgical interventions and post-operative animal care were carried out in accordance with the NIH Guide for the Care and Use of Laboratory Animals and were approved by the Chinese National Committee to the Use of Experimental Animals for Medical Purposes, Jiangsu Branch. All efforts were made to minimize the number of animals used and their suffering.

\section{Cerebral Water Content (CWC) Measurements}

For time course of ICH-induced brain edema evaluation, animals were anesthetized with $4 \%$ chloral hydrate and decapitated at 1 h, 6 h, 12 h, 1 day, 2 days, 3 days, and 7 days after ICH. For drug dosage effect and time validity evaluation, animals were anesthetized with $4 \%$ chloral hydrate and decapitated $24 \mathrm{~h}$ after ICH. The brains were removed and placed in a glass petri dish. CWC was measured with a drying method (Shohami et al., 1993). The cerebellar tissue was discarded, the right and left hemispheres were separated along the anatomic midline, and the wet weight of each hemisphere was measured. The tissues were completely dried in an oven at $100^{\circ} \mathrm{C}$ for 5 days, and the dry weight of each hemisphere was recorded. The percentage water content (\% water) was calculated according to the Elliott formula for each hemisphere: \%water $=[$ (wet weight - dry weight $) /$ wet weight] $\times 100$ (Bierbach et al., 2008).

\section{Evaluation of Motor and Morris Water Maze (MWM) Performance}

Vestibulomotor function was assessed using a wire grip test (Bermpohl et al., 2006). Mice were placed on a metal wire $(45 \mathrm{~cm}$ long) suspended $45 \mathrm{~cm}$ above a foam pad and were allowed to traverse the wire for $60 \mathrm{~s}$. The latency that a mouse remained on the wire within a 60-s interval was measured, and wire grip scores were quantitated using a 5-point scale. A score of 1 point was given if the mouse failed to hold on to the wire with both sets of forepaws and hind paws together; 2 points were given if the mice held on to the wire with both forepaws and hind paws but not the tail; 3 points were given if the mouse used its tail along with both forepaws and both hind paws; 4 points were given if the mouse moved along the wire on all four paws plus tail; and 5 points were given if mice that scored 4 points also ambulated down one of the posts used to support the wire. Mice that were unable to remain on the wire for less than $30 \mathrm{~s}$ were given a score of zero. The wire grip test was performed in triplicate, and an average value was calculated for each mouse on each day of testing.

The MWM task was used to evaluate spatial memory performance as described previously (Bermpohl et al., 2006; Mannix et al., 2011). The apparatus consisted of a circular blackcolored water tank (120 cm in diameter and $50 \mathrm{~cm}$ high) filled with water to 29 -cm depth with several highly visible cues located on the walls of each of the four quadrants. The water in the tank was colored by black non-toxic food pigment, and the temperature was maintained at $21-25^{\circ} \mathrm{C}$. A clear plexiglass goal platform $5 \mathrm{~cm}$ in diameter was positioned $0.5 \mathrm{~cm}$ below the water's surface approximately $15 \mathrm{~cm}$ from the southwest wall. Each mouse was subjected to a series of four to eight trials per day. For each trial, mice were randomized to one of four starting locations (north, south, east, or west) and placed in the pool facing the wall. Mice were given a maximum of $60 \mathrm{~s}$ to find the submerged platform. If the mouse failed to reach the platform by the allotted time, it was placed on the platform by the experimenter and allowed to remain there for $10 \mathrm{~s}$. Mice were placed in a warming chamber for at least $4 \mathrm{~min}$ between trials. To control for possible differences in visual acuity or sensorimotor function between groups, two trials were performed using a visible platform raised $0.5 \mathrm{~cm}$ above the surface of the water. Performance in the MWM was quantitated by latency to find the platform. To minimize potential variability in performance due to daily environmental differences, mice were always tested concomitantly in motor and MWM tasks. The time to reach the visible platform was recorded and analyzed. Trajectories and latencies of trials were monitored and achieved using a video camera and analyzed with a tracking device and software (Chronotrack 3.0, San Diego Instruments).

\section{Administration of Propidium lodide (PI) and Detection of PI-Positive Cells}

PI $(10 \mathrm{mg} / \mathrm{ml}$; Sigma-Aldrich Corporation, St. Louis, MO, United States) was diluted in $0.9 \% \mathrm{NaCl}$ and $0.4 \mathrm{mg} / \mathrm{kg}$ was administered $1 \mathrm{~h}$ before killing by intraperitoneal injection in a total volume of not more than $100 \mu \mathrm{l}$ (Whalen et al., 2008; Park et al., 2012). Mice were killed at $24 \mathrm{~h}$ after brain injury, brain was frozen in nitrogen vapor, and cryostat brain sections $(12 \mu \mathrm{m})$ were cut at 150 - to $200-\mu \mathrm{m}$ intervals from the anterior to posterior hippocampus (bregma -1.90 to -3.00$)$. The cryostat sections were placed on poly-L-lysine slides and stored at $-80^{\circ} \mathrm{C}$. All cortical regions of the brain were chosen from $200 \times$ cortical fields from within contused cortex. PI-positive cells were quantitated in the cortex and hippocampus in three brain sections separated by at least 150 $200 \mu \mathrm{m}$ (Whalen et al., 2008). For detection of PI-labeled cells, brain sections were fixed in $100 \%$ ethanol for $10 \mathrm{~min}$ at room temperature, coverslipped with Permount (Biomeda, Foster City, CA, United States), and photographed on a Nikon Eclipse T300 fluorescence microscope (Tokyo, Japan) using excitation/emission filters at 568/585 $\mathrm{nm}$ for PI.

\section{Double Immunofluorescence Staining}

All sections were first blocked with 10\% normal serum blocking solution species the same as the secondary antibody, containing $3 \%(\mathrm{w} / \mathrm{v})$ BSA and $0.1 \%$ Triton X-100 and $0.05 \%$ Tween 20 $2 \mathrm{~h}$ at room temperature in order to avoid unspecific staining. The sections were then incubated with different markers as follows: NeuN (neuron marker, 1:200; Abcam), glial fibrillary acidic protein (GFAP) (astrocyte marker, 1:200; Abcam), and CD11b (microcyte marker, 1:200; Abcam). Briefly, sections were incubated with both primary antibodies overnight at $4^{\circ} \mathrm{C}$, followed by a mixture of fluorescein isothiocyanate-conjugated secondary antibodies for $2 \mathrm{~h}$ at $4^{\circ} \mathrm{C}$. The stained sections were examined with a Leica spectral confocal microscope (Germany). 


\section{Hemorrhagic Injury Volume Analysis}

At $24 \mathrm{~h}$ after ICH, mice ( $n=6$ /group) were killed and brains were harvested, fixed in $4 \%$ paraformaldehyde for $24 \mathrm{~h}$, and cryoprotected in serial phosphate-buffered sucrose solutions (10, 20 , and $30 \%$ ) at $4^{\circ} \mathrm{C}$, and then cut into $15-\mu \mathrm{m}$ sections with a cryostat and $150 \mu \mathrm{m}$ apart. Sections were stained with cresyl violet before being quantified for injury volume with Sigmacan Pro 5. Six coronal slices from different levels of the injured hemorrhagic area were summed, and the volumes in cubic millimeters were calculated by multiplying the thickness by the measured areas (Zhang et al., 2014). Six mice per group were analyzed by an observer blind to the experimental treatment.

\section{Western Blot Analysis}

Mice were given an overdose of chloral hydrate and sacrificed at different time points postoperatively $(n=3$ for each time point); tissues from the striatum of the injured hemisphere surrounding the wound (extending $2 \mathrm{~mm}$ to the incision) were for detecting the expression of protein by Western blotting technique, respectively. To prepare lysates, frozen brain tissue samples were minced with eye scissors in ice. The samples were then homogenized in lysis buffer [ $1 \% \mathrm{NP}-40,50 \mathrm{mmol} / \mathrm{L}$ tris, $\mathrm{pH} 7.5,5 \mathrm{mmol} / \mathrm{L}$ EDTA, 1\% SDS, 1\% sodium deoxycholate, $1 \%$ Triton X-100, $1 \mathrm{mmol} / \mathrm{L}$ phenylmethylsulfonyl fluoride (PMSF), $10 \mu \mathrm{g} / \mathrm{ml}$ aprotinin, and $1 \mu \mathrm{g} / \mathrm{ml}$ leupeptin] and clarified by centrifugation for $20 \mathrm{~min}$ in a microcentrifuge at $4^{\circ} \mathrm{C}$. After determination of its protein concentration with the Bradford assay (Bio-Rad), the resulting supernatant (20 $\mu \mathrm{g}$ of protein) was subjected to sodium dodecyl sulfate (SDS)polyacrylamide gel electrophoresis (PAGE). The separated proteins were transferred to a polyvinylidene difluoride membrane (Millipore) by a transfer apparatus at $350 \mathrm{~mA}$ for $1.5 \mathrm{~h}$. The membrane was then blocked with 5\% non-fat milk and incubated with primary antibody against CBS (1:200; Santa Cruz Biotechnology, Santa Cruz, CA, United States), 3-mercaptopyruvate sulfurtransferase (MPST) (1:200; Santa Cruz Biotechnology, Santa Cruz, CA, United States), caspase 3 (1:500; Bioworld Technology, Minneapolis, MN, United States), Bcl-2 (1:1,000; Bioword Technology, Minneapolis, MN, United States), Beclin-1 (1:500; Santa Cruz Biotechnology, Santa Cruz, CA, United States), LC3B (1:3,000; Abcam, Cambridge, MA, United States), P62 (1:500; Santa Cruz Biotechnology, Santa Cruz, CA, United States), or actin (1:200; Santa Cruz Biotechnology, Santa Cruz, CA, United States). After incubating with an anti-rabbit or anti-mouse horseradish peroxidaseconjugated secondary antibody, protein was visualized using an enhanced chemiluminescence system (ECL, Pierce Company, United States).

\section{Statistics Analysis}

All data were expressed as mean \pm standard error of the mean (SEM). PI-positive cell count was analyzed by the rank sum test. Motor and MWM test data (hidden and visible platform acquisition latencies) were analyzed by two factor repeated-measures analysis of variance (ANOVA; for group and time) followed by post hoc Bonferroni's test for multiple comparisons. Data on the probe trial were analyzed using oneway ANOVA analysis followed by post hoc Tukey's test for multiple comparisons. Western blot data were carried out by oneway ANOVA with Dunnett's $t$ test. All analyses were performed with SPSS statistical package (version 13.0 for Windows, SPSS Inc., United States). For all comparisons, $P<0.05$ was regarded as significant.

\section{RESULTS}

\section{$\mathrm{H}_{2} \mathrm{~S}$ Attenuates ICH-Induced Brain Edema Through Endogenous $\mathrm{H}_{2} \mathrm{~S}$ Synthesis Pathway in Mice}

The percentage of brain water content significantly increased in the injured ipsilateral cortex after ICH. Brain water content in the injured hemisphere was increased starting at $1 \mathrm{~h}$ and peaking 1 day post-ICH compared with the contralateral hemisphere and sham group. Pretreatment with NaHS at doses of 1-25 $\mu \mathrm{mol} / \mathrm{kg}$ $30 \mathrm{~min}$ before ICH can reduce brain water content ipsilateral to the injury, but NaHS with doses of 50 or $100 \mu \mathrm{mol} / \mathrm{kg}$ has no protective effect. Pretreatment with NaHS at doses of $25 \mu \mathrm{mol} / \mathrm{kg}$ $30 \mathrm{~min}$ before or $1 \mathrm{~h}$ after ICH attenuated $\mathrm{ICH}$-induced brain edema (Figure 1). On the other hand, the combined treatment of $\mathrm{H}_{2} \mathrm{~S}$ and AOAA exerted no greater inhibition of brain edema, suggesting that treatment with exogenous $\mathrm{H}_{2} \mathrm{~S}$ can attenuate the development of brain water content induced by $\mathrm{ICH}$ through the endogenous $\mathrm{H}_{2} \mathrm{~S}$ synthesis pathway.

\section{Exogenous $\mathrm{H}_{2} \mathrm{~S}$ Induces CBS Expression and $\mathrm{H}_{2} \mathrm{~S}$ Production Through the Endogenous $\mathrm{H}_{2} \mathrm{~S}$ Synthesis Pathway}

We found that $\mathrm{ICH}$ led to a significant decrease in expression of $\mathrm{CBS}$ and $\mathrm{H}_{2} \mathrm{~S}$ production compared with the sham group. Compared with the ICH group, NaHS supplementation induces CBS expression and $\mathrm{H}_{2} \mathrm{~S}$ production. CBS inhibitor AOAA has no impact on CBS expression, but it reduces $\mathrm{H}_{2} \mathrm{~S}$ production in the sham group, suggesting that AOAA reduces the production of $\mathrm{H}_{2} \mathrm{~S}$ by blocking the $\mathrm{H}_{2} \mathrm{~S}$-producing activity of CBS enzyme instead of decreasing CBS expression. When treated with $\mathrm{NaHS}$ and AOAA, there is no change in CBS expression and $\mathrm{H}_{2} \mathrm{~S}$ production compared with the $\mathrm{ICH}$ group (Figure 2). $\mathrm{NaHS}$ supplementation cannot induce CBS expression and $\mathrm{H}_{2} \mathrm{~S}$ production in ICH mice when treated with AOAA. We also detected the expression of other $\mathrm{H}_{2} \mathrm{~S}$-producing enzymes, such as 3-MST, and ICH led to no change in the expression of 3-MST compared with the sham group (Figure 2).

\section{$\mathrm{H}_{2} \mathrm{~S}$ Attenuates Spatial Memory Impairment and Motor Deficits After ICH}

In order to determine whether $\mathrm{H}_{2} \mathrm{~S}$ could improve spatial memory acquisition and motor function, we performed the neurofunctional assessment using behavior tests.

There was no significant differences between groups before $\mathrm{ICH}$ in the baseline of motor function. ICH elicited a significant 


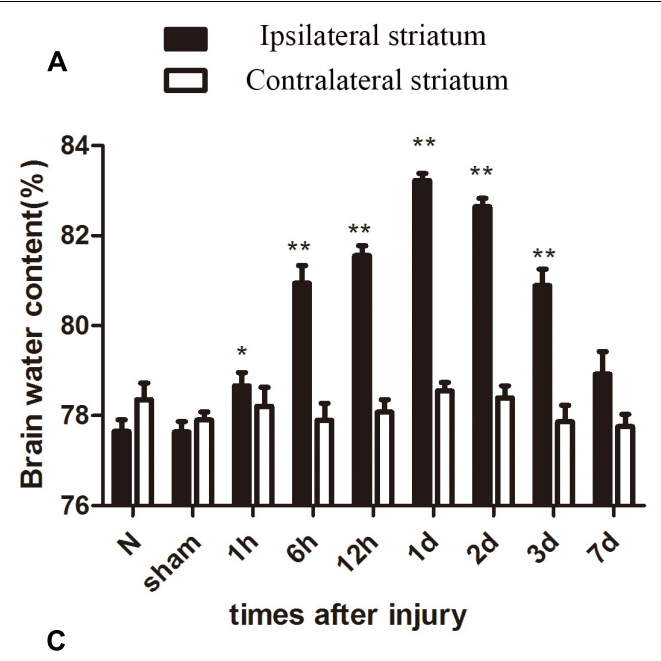

B
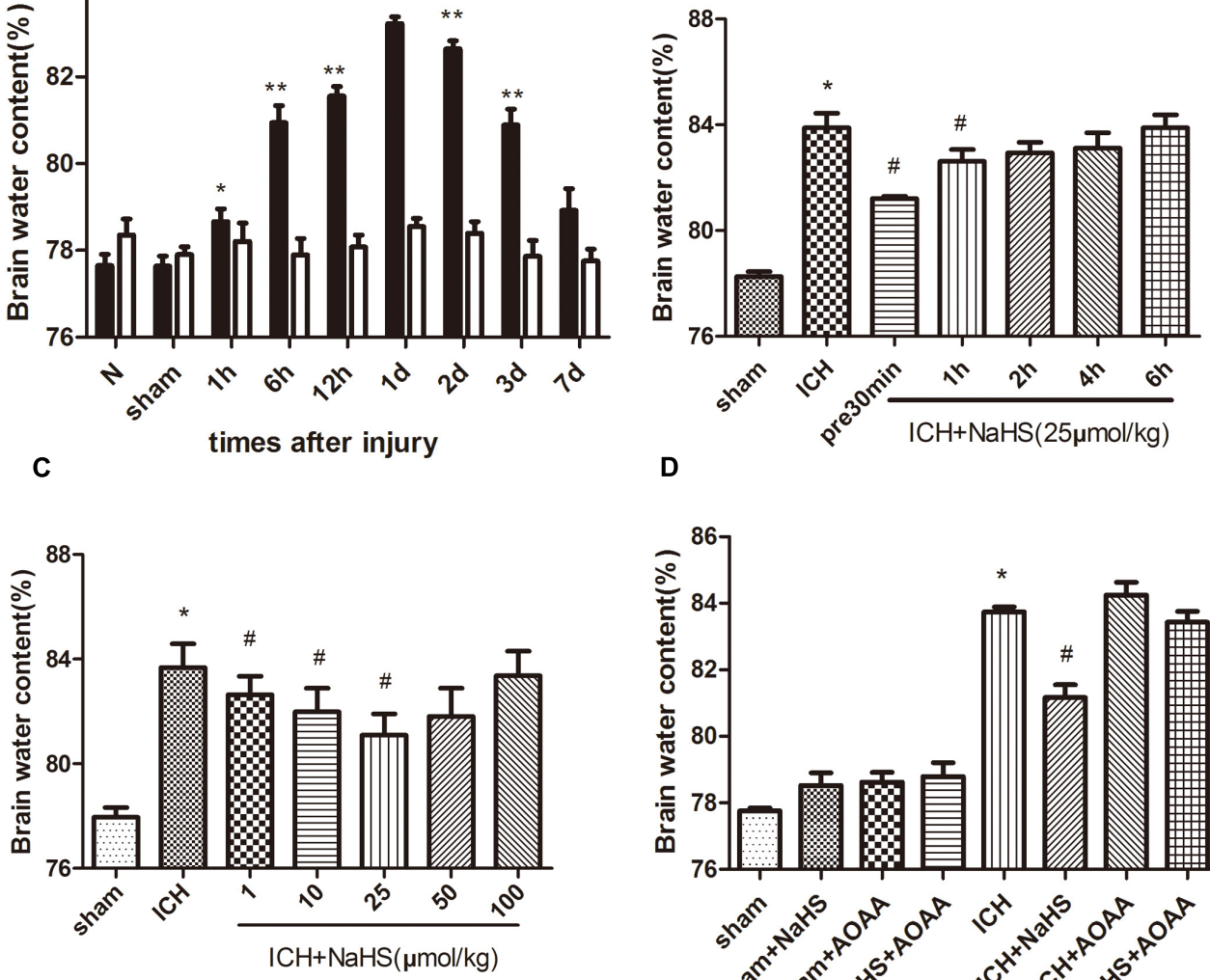

D

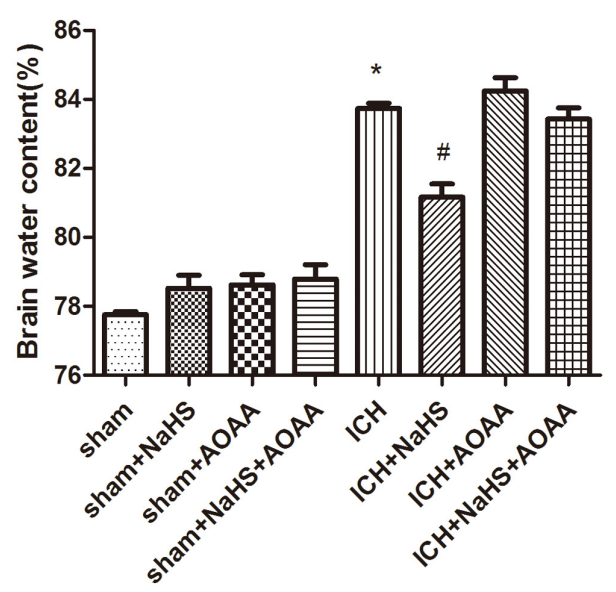

FIGURE 1 | Treatment with $\mathrm{H}_{2} \mathrm{~S}$ attenuated ICH-induced brain edema through the endogenous $\mathrm{H}_{2} \mathrm{~S}$ synthesis pathway. (A) The water content of the injured hemisphere and contralateral hemisphere were measured from $1 \mathrm{~h}$ to 7 days after $\mathrm{ICH}$. ${ }^{*} P<0.05$, ${ }^{* *} P<0.01 \mathrm{vs}$. sham group. (B) Injected $\mathrm{H}_{2} \mathrm{~S}(25 \mu \mathrm{mol} / \mathrm{kg}$ ), at 30 min before or 1,2 , 4, or $6 \mathrm{~h}$ post-ICH, and the brain water content was detected at 1 day after $\mathrm{ICH}$. ${ }^{*} P<0.05$ vs. Sham group. ${ }^{\#} P<0.05$ vs. ICH group. (C) Pretreatment with $\mathrm{H}_{2} \mathrm{~S}$ at 30 min before $\mathrm{ICH}$ with different dosages from 1 to $100 \mu \mathrm{mol} / \mathrm{kg}$, and brain water content was measured at $1 \mathrm{~d}$ after $\mathrm{ICH}$. ${ }^{*} P<0.05$ vs. sham group. $\# P<0.05$ vs. ICH group. (D) Pretreatment with $\mathrm{H}_{2} \mathrm{~S}$, AOAA, or combined treatment of $\mathrm{H}_{2} \mathrm{~S}$ and $\mathrm{AOAA}$ before ICH, and then the brain water content was measured at 1 day after $\mathrm{ICH}$. ${ }^{*} P<0.05$ vs. sham group. $\# P<0.05$ vs. ICH group. $\mathrm{N}$ indicates the normal group. Data are expressed as mean $\pm \mathrm{SEM}(n=6)$.

decrease in the performance of motor function on days 17, which returned to preinjury levels on day 8 after ICH. Compared with the ICH group, there was a statistically significant improvement in motor recovery and functional outcome with $25 \mu \mathrm{mol} / \mathrm{kg} \mathrm{NaHS}$ supplementation on days 4-7 post-injury (Figure 3). We also found that pretreatment with AOAA alone could not improve the recovery of motor functional outcome post-ICH compared to the ICH group. Moreover, there was no significant improvement in motor recovery and functional outcome with $25 \mu \mathrm{mol} / \mathrm{kg}$ NaHS supplementation on days 4-7 post-injury when subjected to AOAA injection compared to the ICH group (Figure 3).

The MWM was used to evaluate spatial memory and was performed after day 8 when no significant difference in motor function was observed between different groups. In the visible or hidden platform test and probe trial, all groups of mice showed normal acquisition curves and selective quadrant search in
MWM experiments before suffering ICH (Figure 3). Compared with the sham group, there is significant increase in the latencies to search the hidden platform on days 8-14 in the ICH group. Pretreatment with $\mathrm{H}_{2} \mathrm{~S}$ displayed decreased latencies to find the hidden platform on days 10-13 compared with the ICH group, suggesting $\mathrm{H}_{2} \mathrm{~S}$ could improve cognitive and functional recovery following ICH. Pretreatment with AOAA alone could not improve the recovery of cognitive functional outcome post$\mathrm{ICH}$ compared to the ICH group. Moreover, pretreatment with $\mathrm{H}_{2} \mathrm{~S}(25 \mu \mathrm{mol} / \mathrm{kg})$ could not reverse cognitive functional damage if the endogenous $\mathrm{H}_{2} \mathrm{~S}$ production was inhibited by AOAA after ICH compared to the ICH group (Figure 3). We performed visible platform testing on days 16 and 17 during the MWM test in order to avoid bias in the effect of visual acuity. In the visible platform test, no significant difference in latencies to find the visible platform was observed between groups on days 16 and 17. Compared with the sham group, 


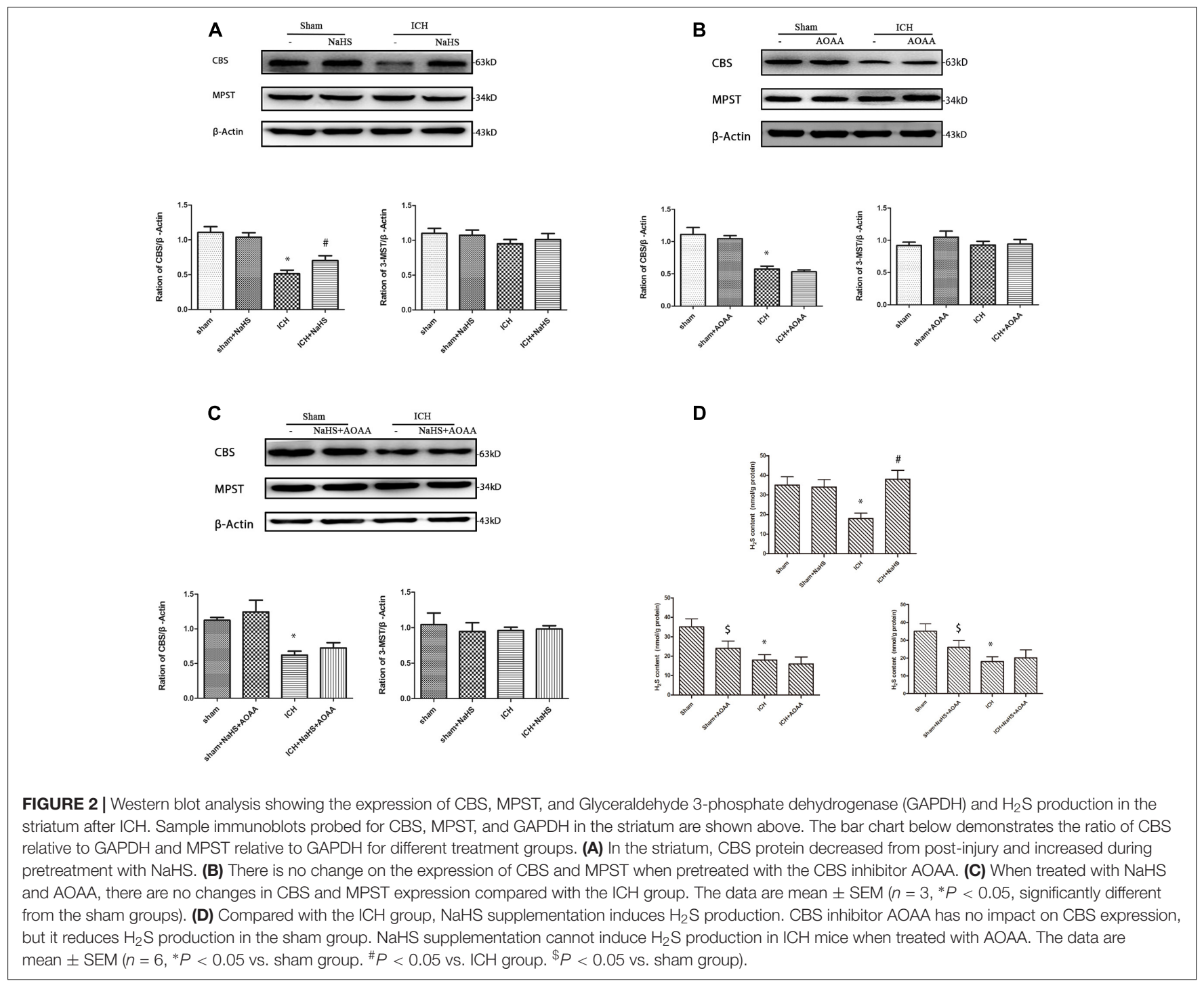

there is a significant decrease in time in the target quadrant in the ICH group in the probe trial. Pretreatment with $\mathrm{H}_{2} \mathrm{~S}$ displayed more time swimming in the target quadrant compared with the ICH group.

\section{$\mathrm{H}_{2} \mathrm{~S}$ Attenuates Hemorrhage Volume and Permeability of Plasmalemma After ICH}

To determine the effect of $\mathrm{H}_{2} \mathrm{~S}$ on hemorrhage volume caused by $\mathrm{ICH}$, cresyl violet stain was used to identify the neuronal structure in the brain $24 \mathrm{~h}$ post-ICH. The results showed that pretreatment with $\mathrm{H}_{2} \mathrm{~S}$ attenuated hemorrhage volume at $24 \mathrm{~h}$ following $\mathrm{ICH}$ (Figure 4). However, pretreatment with $\mathrm{H}_{2} \mathrm{~S}$ could not reduce injury volume if the endogenous $\mathrm{H}_{2} \mathrm{~S}$ production by AOAA after ICH was inhibited, compared to ICH group (Figure 4). No detectable hemorrhage was observed in the sham-operated mice.

The permeability of plasmalemma was used for the detection of early stage of cell death, including autophagic cell death, apoptosis, and necrosis. To interpret cellular mechanisms of reduced hemorrhage volume, we investigated the effect of $\mathrm{H}_{2} \mathrm{~S}$ on plasmalemma permeability in the striatum after injury using in vivo PI staining (Figure 5). Pretreatment with $\mathrm{H}_{2} \mathrm{~S}$ reduced the numbers of PI-positive cells in the striatum at $6 \mathrm{~h}$ following ICH. There were no PI-positive cells to be detected in the striatum of the sham group mice and in the contralateral striatum region of the $\mathrm{ICH}$ mice. However, pretreatment with $\mathrm{H}_{2} \mathrm{~S}$ could not decrease the number of PI-positive cells when inhibiting the endogenous $\mathrm{H}_{2} \mathrm{~S}$ production by AOAA after ICH compared to $\mathrm{ICH}$ group (Figure 5). In order to distinguish the cell type of the PIpositive cells, we used double immunofluorescence staining for PI with NeuN (neuronal marker), PI with GFAP (astrocyte marker), and PI with CD11b (microglia marker). Double immunofluorescence staining revealed that there was more colocalization between NeuN and PI (Figure 6). The GFAPexpressing astrocyte or CD11b-expressing microglia partly showed as PI positive. These results suggested that ICH induced neuronal death in the striatum following $\mathrm{ICH}$, and 
A

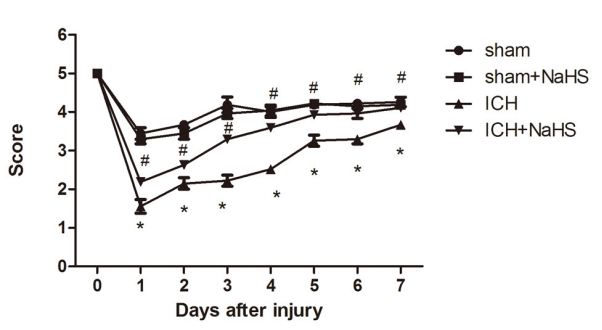

C

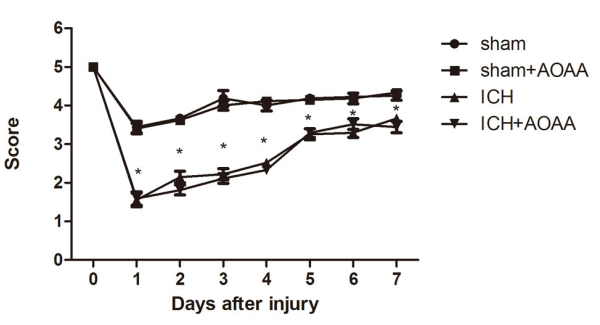

E

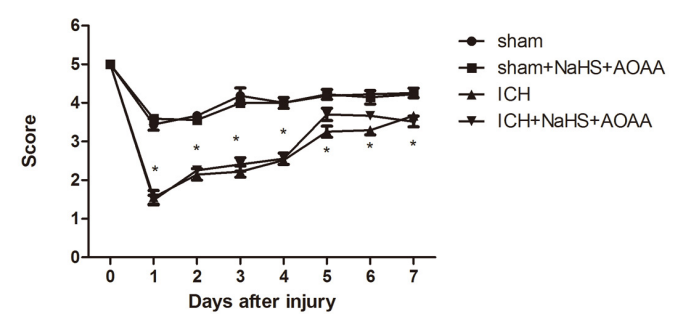

B

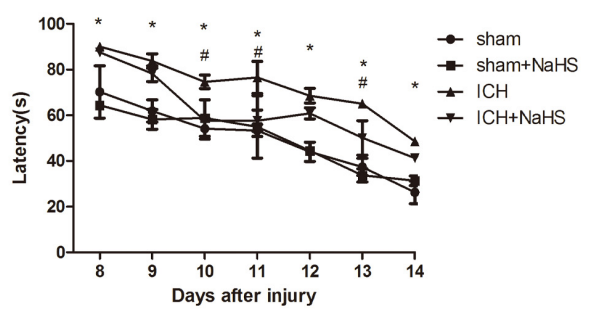

D

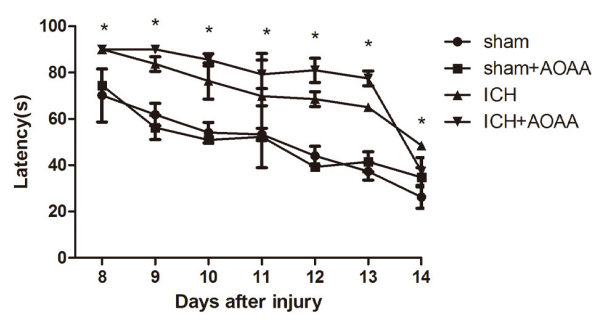

$\mathbf{F}$

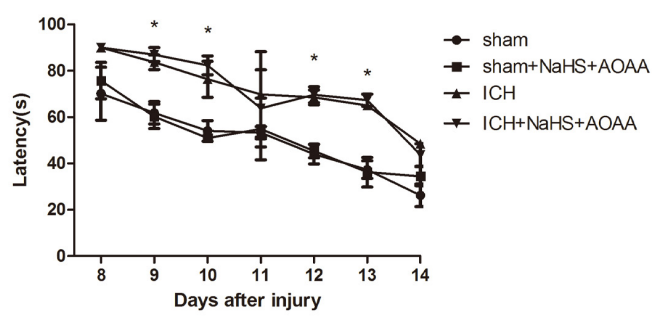

FIGURE $3 \mid \mathrm{H}_{2} \mathrm{~S}$ improved the recovery of $\mathrm{ICH}$-induced motor deficits and improved spatial memory acquisition through the endogenous $\mathrm{H}_{2} \mathrm{~S}$ synthesis pathway. (A,C,E) Motor function was assessed by a wire grip test. No difference in baseline motor function before ICH was observed between groups of mice administered with $\mathrm{H}_{2} \mathrm{~S}$. Pretreatment with $\mathrm{H}_{2} \mathrm{~S}$ speeds up the recovery of motor function deficits in mice compared to the ICH group. Pretreatment with AOAA alone could not improve the recovery of motor functional outcome post-ICH compared to the $\mathrm{ICH}$ group. Moreover, pretreatment with $\mathrm{H}_{2} \mathrm{~S}$ could not improve the recovery of motor functional outcome on days 4-7 post-ICH when subjected to AOAA injection compared to the ICH group $(* P<0.05$ vs. ICH group, $n=10 /$ group). (B,D,F) Mice in the $\mathrm{ICH}$ group had significantly longer escape latency compared with sham group in the hidden platform task; however, ICH + NaHS group had significantly lower escape latency compared with the $\mathrm{ICH}$ group. Pretreatment with AOAA alone could not improve the recovery of cognitive functional outcome post-ICH compared to the $\mathrm{ICH}$ group. Moreover, pretreatment with $\mathrm{NaHS}$ could not reverse cognitive functional damage if the endogenous $\mathrm{H}_{2} \mathrm{~S}$ production was inhibited by AOAA post-ICH compared to the $\mathrm{ICH}$ group. There was no significant difference in escape latency in all four groups in the visible platform task $\left(^{*} P<0.05\right.$ vs. sham group; $\# P<0.05$ vs. ICH group, $n=10 /$ group).

pretreatment with $\mathrm{H}_{2} \mathrm{~S}$ may reduce neuronal death in the striatum following ICH.

\section{$\mathrm{H}_{2} \mathrm{~S}$ Inhibits the Activation of Caspase3 and the Reduction in Bcl-2}

Because loss of plasmalemma integrity is in the early stage of cell death, we investigated whether pretreatment with $\mathrm{H}_{2} \mathrm{~S}$ could inhibit the activation of cell apoptosis in the striatum at $24 \mathrm{~h}$ after ICH by detecting the expression of caspase 3 and Bcl-2 (Figure 7). There was a significant increase in the expression of cleaved caspase 3 and a decrease in the expression of Bcl-2 in the injured striatum at $24 \mathrm{~h}$ following ICH. However, pretreatment with $\mathrm{H}_{2} \mathrm{~S}$ inhibited the activation of caspase 3 and the reduction in Bcl-2, suggesting pretreatment with $\mathrm{H}_{2} \mathrm{~S}$ could inhibit the activation of cell apoptosis in the injured striatum. However, pretreatment with $\mathrm{H}_{2} \mathrm{~S}$ could not suppress cell apoptosis induced by ICH if the endogenous $\mathrm{H}_{2} \mathrm{~S}$ production was inhibited by AOAA post-ICH compared to the ICH group (Figure 7).

\section{$\mathrm{H}_{2} \mathrm{~S}$ Reversed the Upregulation of LC3 and Beclin-1 and the Downregulation of p62 Induced by ICH}

We detected the expression of LC3II, p62, and Beclin-1 by Western blotting assay in order to determine whether pretreatment with $\mathrm{H}_{2} \mathrm{~S}$ could inhibit the activation of autophagy (Figure 8). The expressions of LC3II and Beclin-1 protein are the specific markers of autophagy, reflecting the progress of autophagy such as autophagosome formation and maturity. p62 protein serves as a useful marker for monitoring the autophagic flux, which reflects autophagic clearance of protein aggregate (Ichimura et al., 2008). Therefore, we detected the expression of LC3II and Beclin-1 and then found that there was a significant increase in the expression of LC3II and Beclin-1 in the striatum 
A
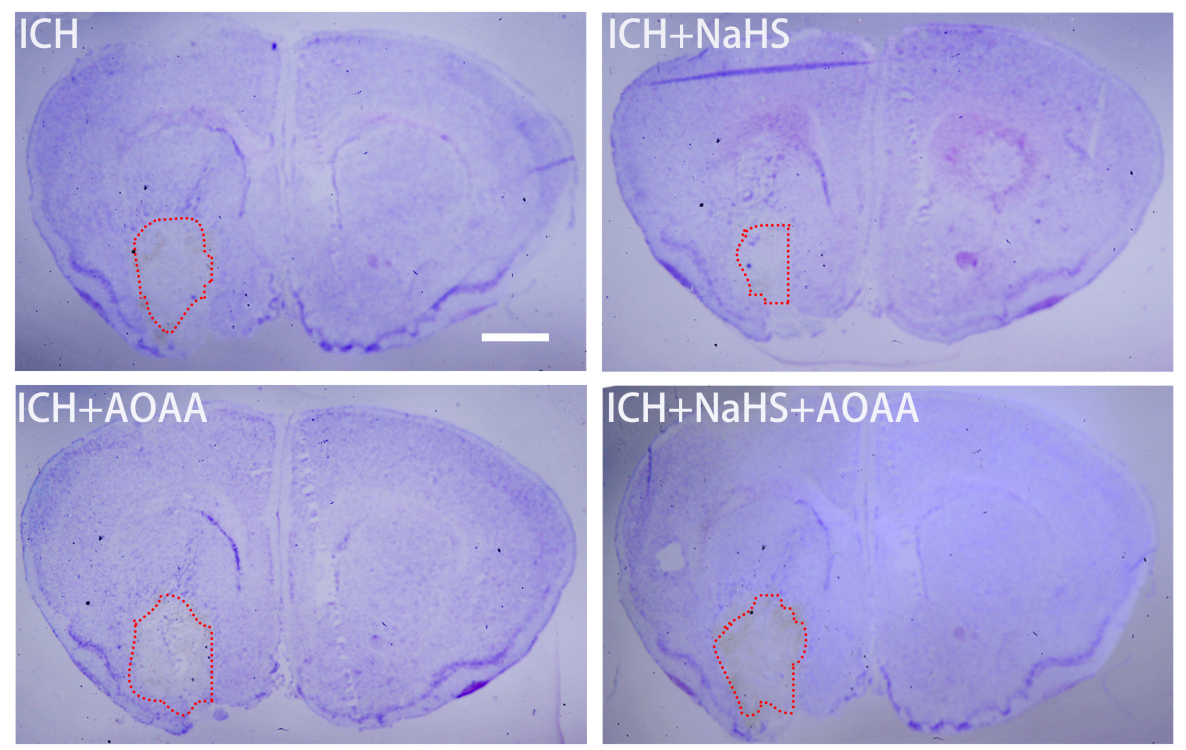

B

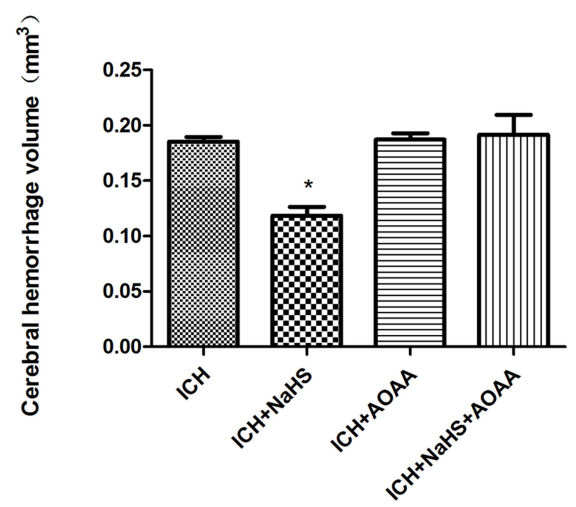

FIGURE 4 | Pretreatment with $\mathrm{H}_{2} \mathrm{~S}$ reduces injury volume at $24 \mathrm{~h}$ after ICH in the injured striatum. (A) Coronal sections were collected at $24 \mathrm{~h}$ after ICH and stained for cresyl violet. Pretreatment with $\mathrm{H}_{2} \mathrm{~S}$ reduced injury volume after $\mathrm{ICH}$ in mice. However, pretreatment with $\mathrm{H}_{2} \mathrm{~S}$ could not reduce injury volume if the endogenous $\mathrm{H}_{2} \mathrm{~S}$ production was inhibited by AOAA post-ICH compared to the $\mathrm{ICH}$ group. (B) Quantification shows that brain injury volume was significantly smaller in the $\mathrm{H}_{2} \mathrm{~S}$-treated mice than in the $\mathrm{ICH}$ group mice ${ }^{*} P<0.05$ vs. ICH group, $n=6$ in each group). Scale bars: $1 \mathrm{~mm}$.

following ICH. However, pretreatment with $\mathrm{H}_{2} \mathrm{~S}$ inhibited the upregulation of LC3II and Beclin-1, suggesting $\mathrm{H}_{2} \mathrm{~S}$ could inhibit the activation of autophagy in the injured striatum (Clark et al., 2008). There was a significant decrease in the expression of p62 in the striatum following $\mathrm{ICH}$, and pretreatment with $\mathrm{H}_{2} \mathrm{~S}$ restored p62 protein level to the preinjury range. Furthermore, we detected the expression of LC3II, p62, and Beclin-1 in the ICH group when pretreated with AOAA or pretreated with NaHS and AOAA, and then we found that $\mathrm{H}_{2} \mathrm{~S}$ synthesis inhibitor AOAA inhibited the protective effects of $\mathrm{H}_{2} \mathrm{~S}$ (Figure 8).

\section{DISCUSSION}

Hemorrhagic stroke (ICH) is caused by sudden blood vessel rupture, which accounts for the remaining $10 \%-15 \%$ of strokes. It is a pathological accumulation of blood in the brain parenchyma and is associated with high mortality and morbidity (Bobinger et al., 2018). Although we have much knowledge about the molecular pathophysiology of $\mathrm{ICH}$ on the cellular level, we have not yet developed a safe and effective neuroprotective drug to prevent cell damage caused by stroke. An ideal neuroprotectant would be high permeability to the blood-brain barrier (BBB), which played a protective role during the processes of nerve injury and had considerable efficacy and safety. Over the last few decades, there is significant progress achieved in delineating the therapeutic potentials and molecular mechanisms underlying the actions of $\mathrm{H}_{2} \mathrm{~S}$ on brain diseases (Paul and Snyder, 2018). Our previous study demonstrated that $\mathrm{H}_{2} \mathrm{~S}$ provided neuroprotection in TBI via inhibition of autophagy and apoptosis, but the molecular mechanisms 
A
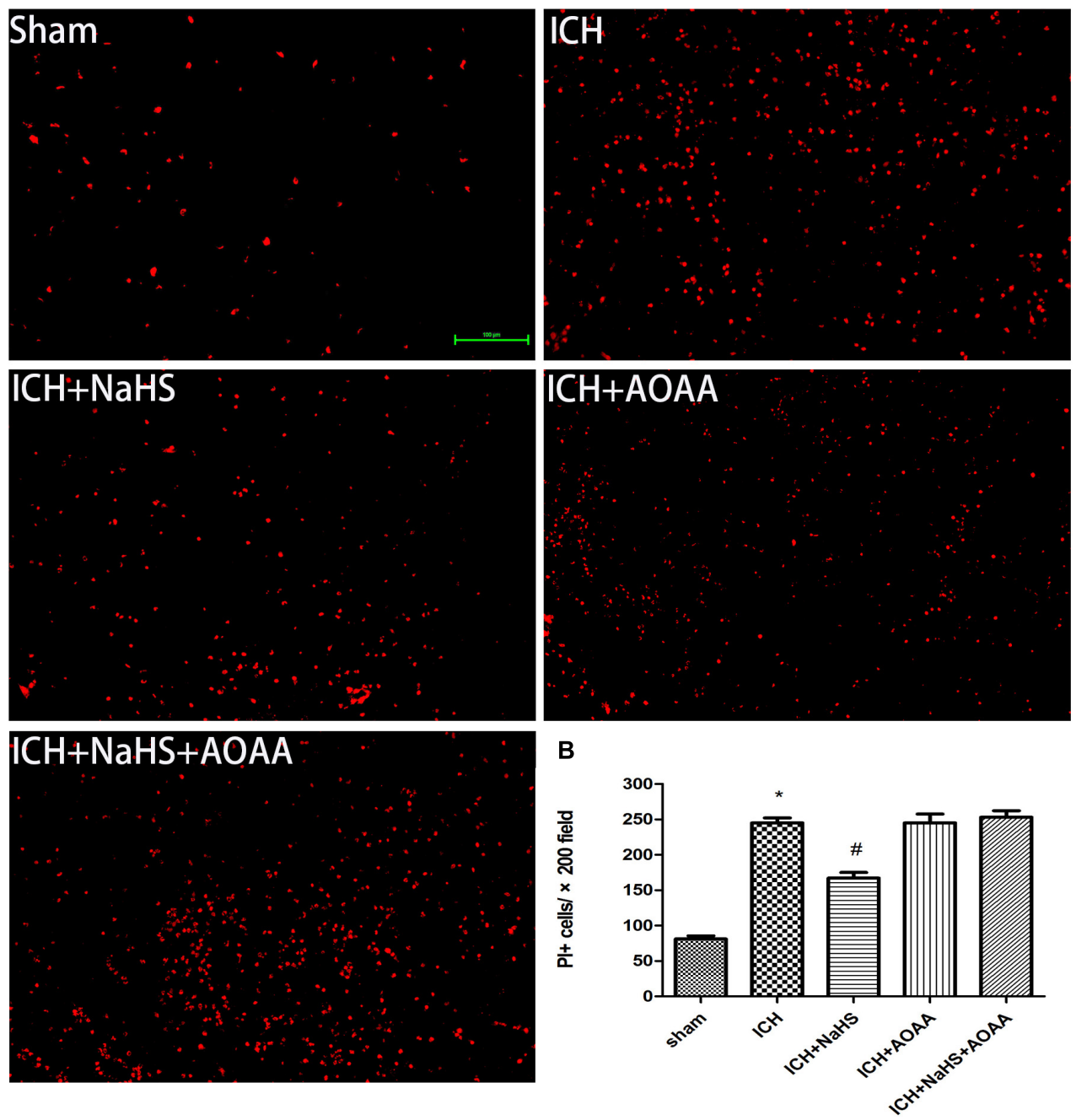

FIGURE 5 | Pretreatment with $\mathrm{H}_{2} \mathrm{~S}$ reduces PI-positive cells after ICH in the injured striatum. (A) Representative photomicrographs showed that pretreatment with $\mathrm{H}_{2} \mathrm{~S}$ reduced numbers of $\mathrm{PI}$-positive cells in the striatum brain regions after brain injury in the $\mathrm{ICH}+\mathrm{NaHS}$ group compared to the ICH group. In contrast to injured mice, PI-positive cells were not detected in brain regions from the sham group or in the contralateral hemisphere of the injured mice. However, pretreatment with $\mathrm{H}_{2} \mathrm{~S}$ could not decrease the number of PI-positive cells when inhibiting endogenous $\mathrm{H}_{2} \mathrm{~S}$ production by AOAA compared to the ICH group. Original magnification $\times 200$. (B) Quantitation of Pl-positive cells in the injured striatum regions. ${ }^{*} P<0.05$ vs. sham group. ${ }^{\#} P<0.05$ vs. ICH group $(n=10$ per group).

involved in the cytoprotective effect of $\mathrm{H}_{2} \mathrm{~S}$ after brain injury have not been investigated (Zhang et al., 2014). A gap still exists between neuroprotection effect of exogenous $\mathrm{H}_{2} \mathrm{~S}$ and the molecular mechanism of endogenous $\mathrm{H}_{2} \mathrm{~S}$ on brain injury. Moreover, no clear mechanisms of exogenous $\mathrm{H}_{2} \mathrm{~S}$ modulating the endogenous $\mathrm{H}_{2} \mathrm{~S}$ pathway were addressed, and biological effects of endogenous $\mathrm{H}_{2} \mathrm{~S}$ synthase inhibitors were not investigated after ICH. In order for us to develop therapies designed to stimulate this repair, we explored potential neuroprotective mechanisms of $\mathrm{H}_{2} \mathrm{~S}$ against ICHinduced injury.

In this study, we demonstrated for the first time that the protective effect of exogenous $\mathrm{H}_{2} \mathrm{~S}$ against $\mathrm{ICH}$ may be not a direct action but an indirect effect through inducing endogenous $\mathrm{H}_{2} \mathrm{~S}$ metabolism responses. Another important observation we made is that AOAA, an inhibitor of CBS, significantly reduced production of endogenous $\mathrm{H}_{2} \mathrm{~S}$, but AOAA has no impact on the expression of CBS, suggesting that AOAA reduced endogenous $\mathrm{H}_{2} \mathrm{~S}$ production through inhibiting the enzyme activity of CBS rather than modulating the expression of the CBS protein level. We also distinguished cell types of PI-positive cells in an in vivo mice ICH model using double immunofluorescence staining PI with NeuN (neuronal marker), PI with GFAP (astrocyte marker), and PI with CD11b (microglia marker). Double immunofluorescence staining revealed that there was more colocalization between NeuN and PI. The GFAP-expressing astrocyte or CD11bexpressing microglia partly showed as PI positive. It suggested 

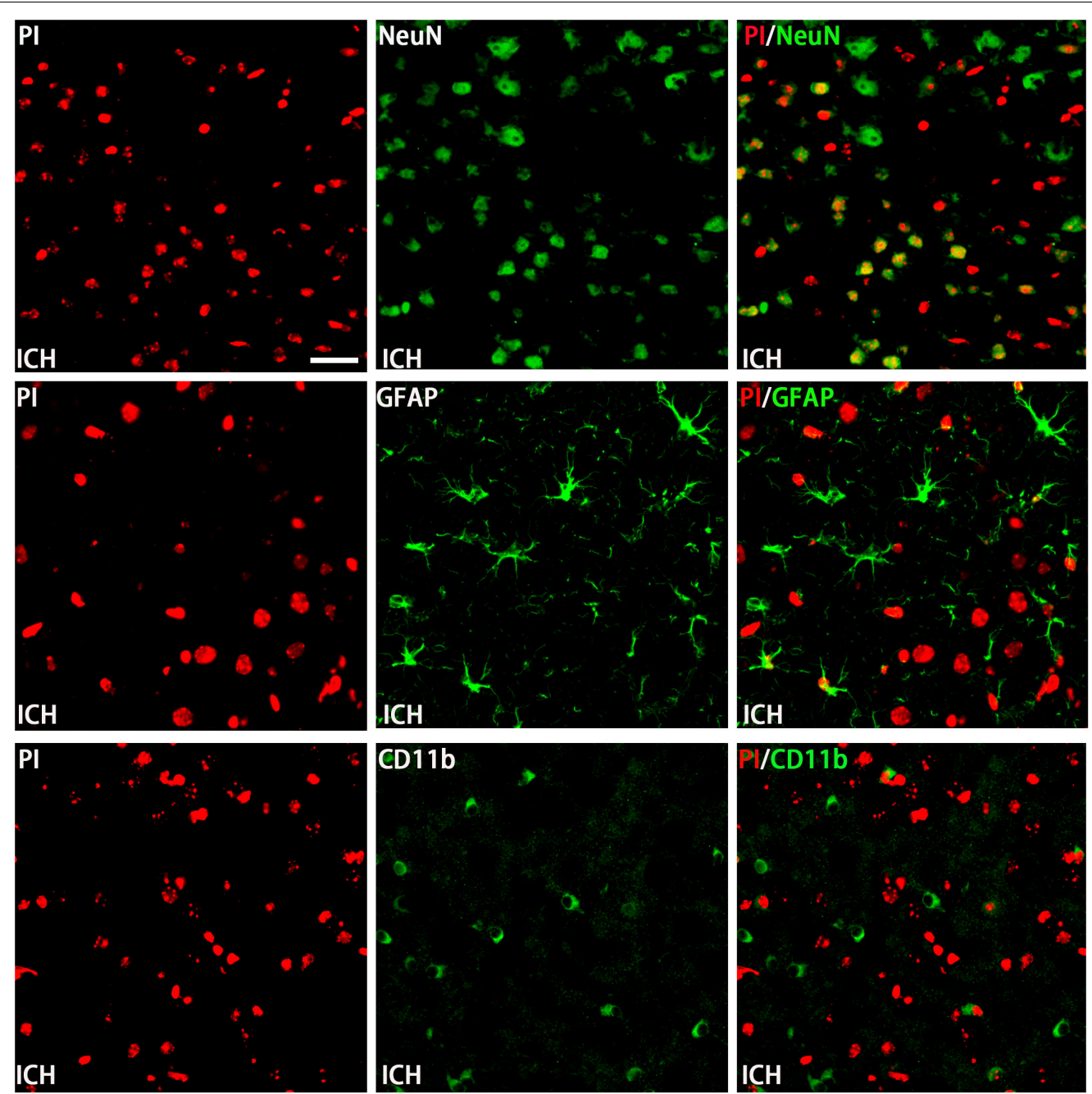

FIGURE 6 | Double immunofluorescence staining for PI with NeuN, GFAP, and CD11b at the first day in the injured striatum after ICH. Coronal sections labeled with PI (red), NeuN (green), GFAP (green), and CD11b (green) and the yellow color visualized in the merged images represented colocalization of PI with NeuN (neuronal marker), PI with GFAP (astrocyte marker), and PI with CD11b (microglia marker). Double immunofluorescence staining revealed that at the first day post-injury, there was more colocalization between NeuN and PI. The GFAP-expressing astrocyte or CD11b-expressing microglia few partly showed as PI positive. Scale bars: $25 \mu \mathrm{m}$.

that $\mathrm{ICH}$-induced neuronal death in the striatum following $\mathrm{ICH}$ and pretreatment with $\mathrm{H}_{2} \mathrm{~S}$ may reduce neuronal death in the striatum following $\mathrm{ICH}$. We also demonstrated that endogenous $\mathrm{H}_{2} \mathrm{~S}$ production was significantly decreased in the striatum after $\mathrm{ICH}$ as a result of a decrease in CBS protein levels. $\mathrm{H}_{2} \mathrm{~S}$ pretreatment also reversed $\mathrm{ICH}$-induced apoptosis and autophagy in injured striatum post-ICH. In addition, we demonstrated that pretreatment with $\mathrm{H}_{2} \mathrm{~S}$ attenuated brain water content and exhibited improved performance in sensory motor and cognitive function following ICH. Cerebral edema, as a marker of secondary injury after $\mathrm{ICH}$, may result in poor prognosis in patients with ICH. There is increasing interest in the mechanisms of secondary brain injury as a therapeutic target. It is therefore of pressing concern to identify cerebral edema as a proof-of-concept alternative to evaluate the feasibility, acceptability, and safety of different types of therapy for ICH (Selim and Norton, 2018). Therefore, cerebral edema is used as the evaluation standard to determine the therapeutic efficiency of $\mathrm{H}_{2} \mathrm{~S}$ on brain damage induced by ICH. In this study, we demonstrated that brain water content in the injured hemisphere was increased starting at $1 \mathrm{~h}$ and peaked 1 day post-ICH. Pretreatment with NaHS at doses of $1-25 \mu \mathrm{mol} / \mathrm{kg} 30 \mathrm{~min}$ before $\mathrm{ICH}$ can reduce ipsilateral brain water content after injury, but NaHS with doses of 50 or $100 \mu \mathrm{mol} / \mathrm{kg}$ has no protective effect. The most effective concentration of $\mathrm{H}_{2} \mathrm{~S}$ against brain edema after $\mathrm{ICH}$ is $25 \mu \mathrm{mol} / \mathrm{kg}$, and the time window for $\mathrm{H}_{2} \mathrm{~S}$ treatment in $\mathrm{ICH}$ is $30 \mathrm{~min}$ prior to hemorrhage onset. We will use the same drug concentration for subsequent studies to explore the efficacy of $\mathrm{H}_{2} \mathrm{~S}$ in attenuating brain injury following ICH.

There are three enzymes for the generation of endogenous $\mathrm{H}_{2} \mathrm{~S}$ in the mammalian cell: CBS, MPST, and cystathionine$\gamma$-lyase (CSE) (Zhang J.Y. et al., 2017). Previous studies have 


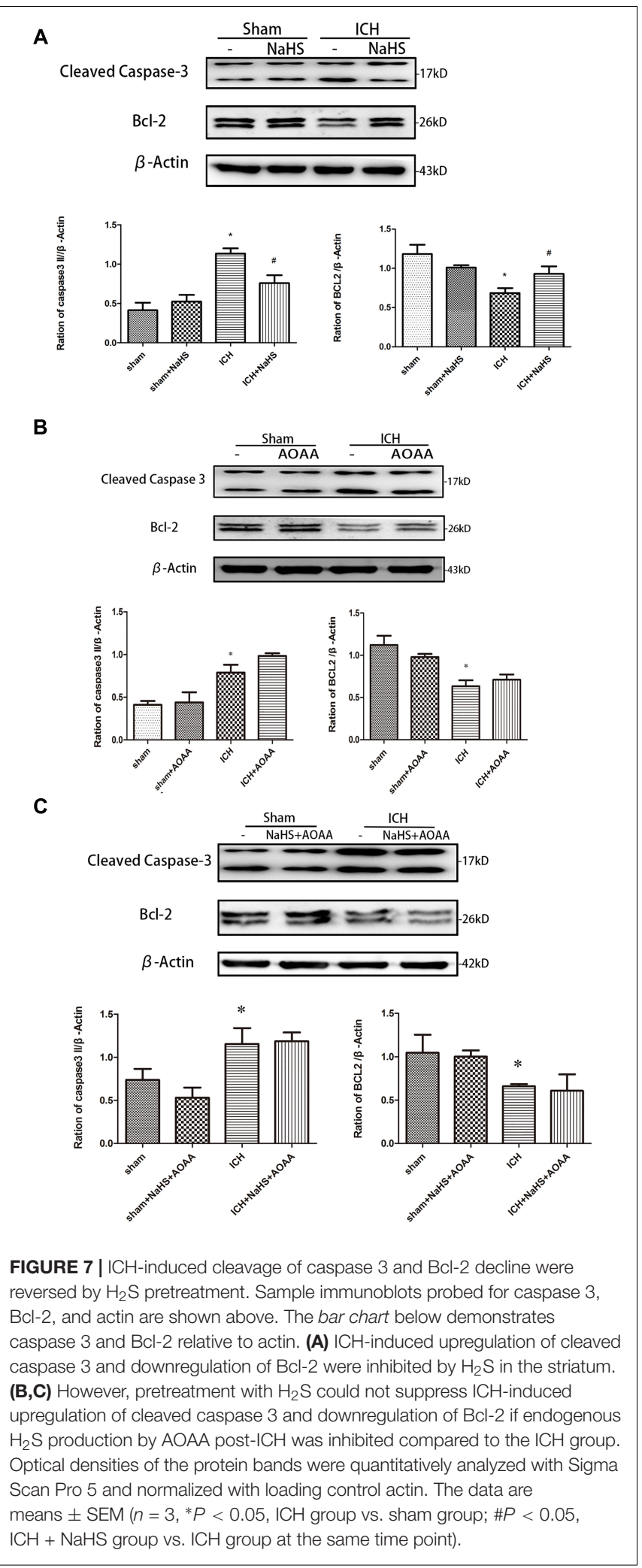

shown that CBS and MPST are major $\mathrm{H}_{2} \mathrm{~S}$-producing enzymes in the brain (Ishigami et al., 2009; Zhang M. et al., 2017). Our results showed that there was a significant decrease in the
A
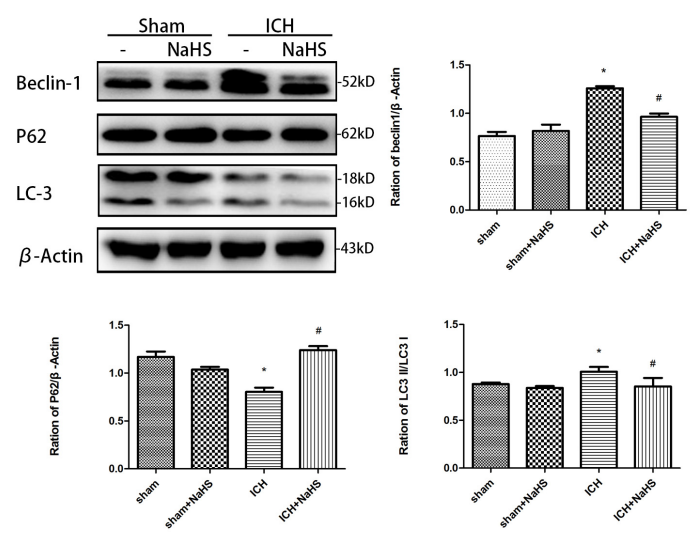

B
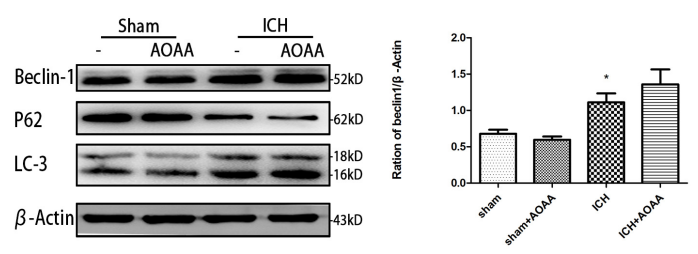

C
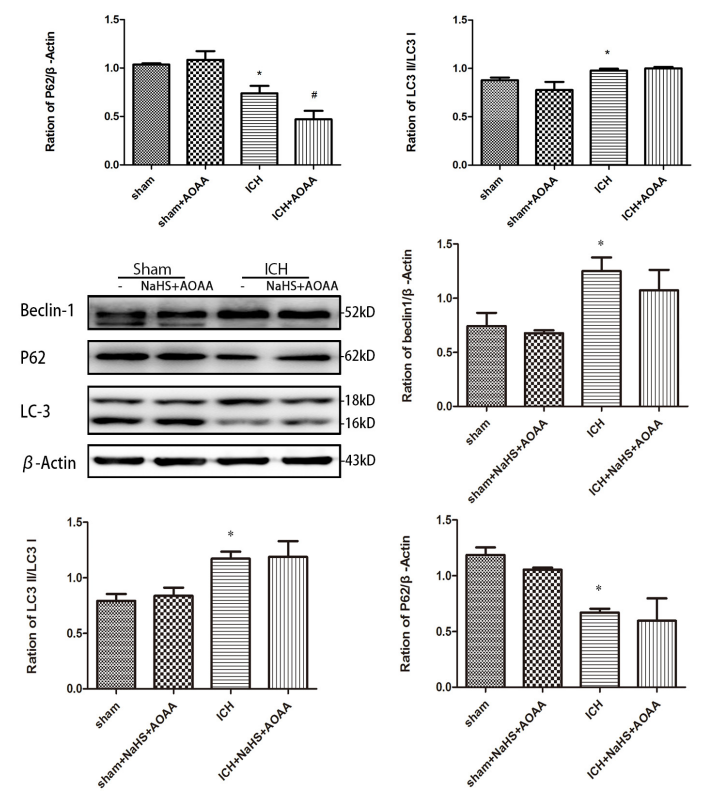

FIGURE 8 | $\mathrm{H}_{2} \mathrm{~S}$ pretreatment reversed ICH-induced LC3II, P62, and Beclin-1 increase. Sample immunoblots probed for LC3II, P62, Beclin-1, and actin are shown above. The bar chart below demonstrates the ratio of LC3II, P62, and Beclin-1 relative to actin. (A) ICH-induced upregulation of LC3II and Beclin-1 and downregulation of $\mathrm{P} 62$ were inhibited by $\mathrm{H}_{2} \mathrm{~S}$ in the striatum. (B,C) However, pretreatment with $\mathrm{H}_{2} \mathrm{~S}$ could not suppress $\mathrm{ICH}$-induced upregulation of LC3II and Beclin-1 and downregulation of P62 if endogenous $\mathrm{H}_{2} \mathrm{~S}$ production by AOAA post-ICH was inhibited compared to the $\mathrm{ICH}$ group. Optical densities of the protein bands were quantitatively analyzed with Sigma Scan Pro 5 and normalized with loading control GAPDH. The data are means $\pm \operatorname{SEM}\left(n=3,{ }^{*} P<0.05, \mathrm{ICH}\right.$ group vs. sham group; $\# P<0.05$, $\mathrm{ICH}+\mathrm{NaHS}$ group vs. ICH group at the same time point). expression of CBS following $\mathrm{ICH}$, but statistically significant differences in the expression of MPST between the two groups were not detected, suggesting that CBS is the major 


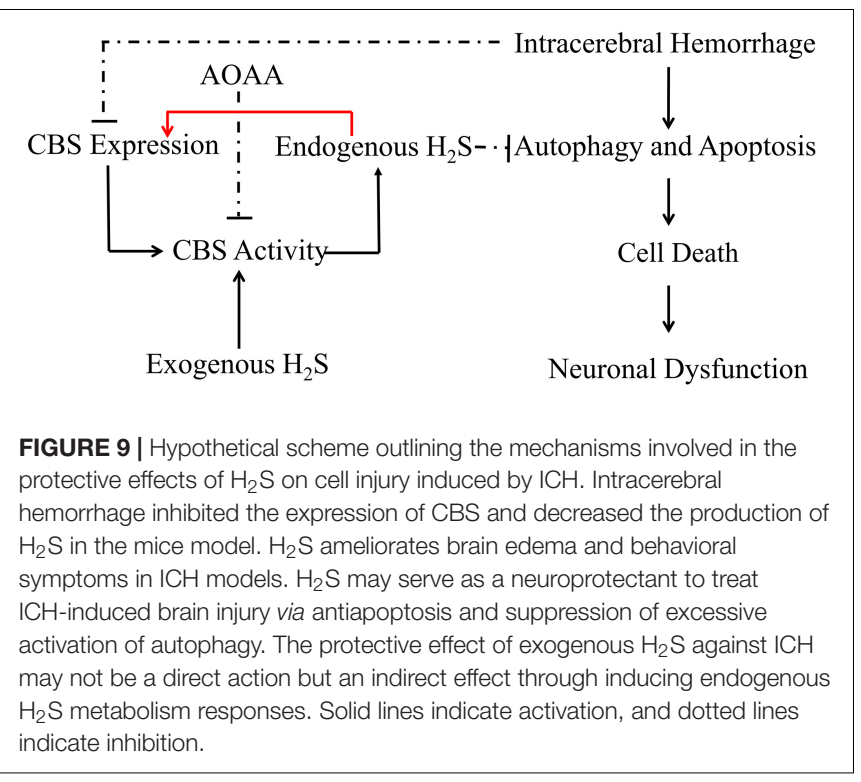

contributor to $\mathrm{H}_{2} \mathrm{~S}$ production in the brain following ICH. Although the molecular mechanism that CBS expression was downregulated following ICH accompanied with unchanged MPST is not clear, we provide further evidence and new results showing that the downregulation of CBS expression plays a vital role in neurologic impairment after injury. NaHS, a classical exogenous $\mathrm{H}_{2} \mathrm{~S}$ donor, significantly increases the expression of CBS and production of endogenous $\mathrm{H}_{2} \mathrm{~S}$ after ICH-induced injury. Another important observation we made is that AOAA, an inhibitor of CBS, significantly reduced production of endogenous $\mathrm{H}_{2} \mathrm{~S}$ after ICH, but AOAA have no impact on the expression of CBS, suggesting that AOAA reduced endogenous $\mathrm{H}_{2} \mathrm{~S}$ production through inhibiting the enzyme activity of CBS rather than modulating the expression of CBS protein level. Moreover, NaHS supplementation cannot induce $\mathrm{CBS}$ expression and $\mathrm{H}_{2} \mathrm{~S}$ production in $\mathrm{ICH}$ mice when treated with AOAA. These data suggest that $\mathrm{NaHS}$ as an exogenous $\mathrm{H}_{2} \mathrm{~S}$ donor mimics the effect of endogenous $\mathrm{H}_{2} \mathrm{~S}$ after ICH via modulating CBS enzyme activity, further indicating that impaired $\mathrm{CBS}-\mathrm{H}_{2} \mathrm{~S}$ signaling axis contributes to brain damage in a mouse model of ICH. AOAA did not produce any significant effect such as cerebral edema in healthy control mice. This also suggested that the role of CBS may not be as important in health as in the disease state.

A majority of patients who are ICH survivors have some neurocognitive impairments, including complex cognitive abilities such as memory and executive function (Garcia et al., 2013; Salihu et al., 2016). In order to determine whether $\mathrm{H}_{2} \mathrm{~S}$ could improve spatial memory acquisition and motor function, we performed a neurofunctional assessment using behavior tests. Pretreatment with $\mathrm{H}_{2} \mathrm{~S}$ displayed significant improvement in motor recovery and cognitive functional outcome following ICH. However, if endogenous $\mathrm{H}_{2} \mathrm{~S}$ production by AOAA was inhibited, pretreatment with NaHS could not reverse cognitive functional damage compared to the ICH group. These results suggested that exogenous $\mathrm{H}_{2} \mathrm{~S}$ displayed significant improvement in motor recovery and cognitive functional outcome following $\mathrm{ICH}$ through the endogenous $\mathrm{H}_{2} \mathrm{~S}$ synthesis pathway. The neuronal cell loss caused by ICH-induced cell death is responsible for significant patient disability, mortality, and morbidity after ICH (Bobinger et al., 2018). Numerous factors that trigger post-ICH pathophysiological pathways lead to cell death in the perihematomal and remote brain regions (Zille et al., 2017). In vivo PI was used to assess plasmalemma damage and cell death after ICH in mice (Zhu et al., 2012; Wang et al., 2013). Double immunofluorescence staining revealed that there was more colocalization between NeuN and PI after ICH. The GFAP-expressing astrocyte or CD11b-expressing microglia partly showed as PI positive. It suggested that ICH induced neuronal death in the striatum. Our results demonstrated pretreatment with $\mathrm{H}_{2} \mathrm{~S}$ decreased the number of PI-positive cells in the injured striatum in mice after $\mathrm{ICH}$, suggesting necrosis contributes to cell demise after ICH. While necrosis is considered nonprogramed cell death, cell death can occur in a programed manner. One example of programed cell death is apoptosis. The morphological hallmarks of apoptosis include cell shrinkage and membrane blebbing with no organelle changes. Caspase 3, a member of the caspase family, has been identified as a key mediator of neuronal programed cell death. It can be activated by two main apoptotic pathways: extrinsic death receptor pathway and intrinsic mitochondrial pathway (Gong et al., 2001; Qureshi et al., 2003). We found that pretreatment with NaHS inhibited the activation of caspase 3 and the reduction in $\mathrm{Bcl}-2$ in the striatum, suggesting that $\mathrm{H}_{2} \mathrm{~S}$ suppressed the activation of apoptosis in the striatum following ICH. Our previous study showed that autophagic cell death was involved in the pathology of $\mathrm{ICH}$, and inhibition of autophagy as a therapeutic strategy provided neuroprotective effect in the ICH model (Shen et al., 2016; Gao et al., 2017). We detected the expression of LC3II, p62, and Beclin-1 by Western blotting assay in order to determine whether pretreatment with $\mathrm{H}_{2} \mathrm{~S}$ could inhibit the activation of autophagy. The results showed that pretreatment with $\mathrm{H}_{2} \mathrm{~S}$ inhibited the upregulation of LC3II and Beclin-1 and the downregulation of p62, suggesting $\mathrm{H}_{2} \mathrm{~S}$ may provide a neuroprotective effect through inhibiting the autophagic cell death pathway. In addition, we detected apoptosis and autophagy when pretreated with NaHS and AOAA, and then we found that $\mathrm{H}_{2} \mathrm{~S}$ synthesis inhibitor AOAA inhibited the protective effects of $\mathrm{H}_{2} \mathrm{~S}$ through the apoptosis and autophagic cell death pathway.

In conclusion, the present study demonstrates that pretreatment with $\mathrm{H}_{2} \mathrm{~S}$ attenuates ICH-induced brain water content and improves behavioral outcomes in a mice model of ICH. $\mathrm{H}_{2} \mathrm{~S}$ exhibits neuroprotective effects through suppressing apoptosis and autophagic cell death following ICH and, therefore, may be recognized as a neuroprotectant in clinical therapy to limit neurological damage following hemorrhagic insults. The protective effect of exogenous $\mathrm{H}_{2} \mathrm{~S}$ against ICH may be not a direct action but an indirect effect through inducing endogenous $\mathrm{H}_{2} \mathrm{~S}$ metabolism responses (Figure 9). 


\section{ETHICS STATEMENT}

All the animal procedures were approved by the Institutional Animal Use and Care Committee at Soochow University and conducted in accordance with the guidelines of Animal Use and Care of the National Institutes of Health (NIH) and the ARRIVE (Animal Research: Reporting In Vivo Experiments). All efforts were made to minimize the numbers of animals used and ensure minimal suffering. In all experiments, data were obtained by investigators blinded to study group.

\section{AUTHOR CONTRIBUTIONS}

MZ, HS, and LT designed the study. HS, PC, JQ, YC, GC, and MZ performed the experiments and analyzed the data. HS, PC, CG,

\section{REFERENCES}

Bermpohl, D., You, Z., Korsmeyer, S. J., Moskowitz, M. A., and Whalen, M. J. (2006). Traumatic brain injury in mice deficient in bid: effects on histopathology and functional outcome. J. Cereb. Blood Flow Metab. 26, 625633. doi: $10.1038 /$ sj.jcbfm. 9600258

Bierbach, B., Meier, M., Kasper-Konig, W., Heimann, A., Alessandri, B., Horstick, G., et al. (2008). Emboli formation rather than inflammatory mediators are responsible for increased cerebral water content after conventional and assisted beating-heart myocardial revascularization in a porcine model. Stroke 39, 213-219. doi: 10.1161/STROKEAHA.107.496620

Bobinger, T., Burkardt, P., Huttner, B. H., and Manaenko, A. (2018). Programmed cell death after intracerebral hemorrhage. Curr. Neuropharmacol. 16, 12671281. doi: 10.2174/1570159X15666170602112851

Clark, R. S., Bayir, H., Chu, C. T., Alber, S. M., Kochanek, P. M., and Watkins, S. C. (2008). Autophagy is increased in mice after traumatic brain injury and is detectable in human brain after trauma and critical illness. Autophagy 4, 88-90. doi: 10.4161/auto.5173

Gao, Y., Ma, L., Luo, C. L., Wang, T., Zhang, M. Y., Shen, X., et al. (2017). IL-33 exerts neuroprotective effect in mice intracerebral hemorrhage model through suppressing inflammation/apoptotic/autophagic pathway. Mol. Neurobiol. 54, 3879-3892. doi: 10.1007/s12035-016-9947-6

Garcia, P. Y., Roussel, M., Bugnicourt, J. M., Lamy, C., Canaple, S., Peltier, J., et al. (2013). Cognitive impairment and dementia after intracerebral hemorrhage: a cross-sectional study of a hospital-based series. J. Stroke Cerebrovasc. Dis. 22, 80-86. doi: 10.1016/j.jstrokecerebrovasdis.2011.06.013

Gong, C., Boulis, N., Qian, J., Turner, D. E., Hoff, J. T., and Keep, R. F. (2001). Intracerebral hemorrhage-induced neuronal death. Neurosurgery 48, 875-882; discussion 882-873. doi: 10.1097/00006123-200104000-00037

Gopalakrishnan, P., Shrestha, B., Kaskas, A. M., Green, J., Alexander, J. S., and Pattillo, C. B. (2018). Hydrogen sulfide: therapeutic or injurious in ischemic stroke? Pathophysiology 26, 1-10. doi: 10.1016/j.pathophys.2018.10.005

Ichimura, Y., Kumanomidou, T., Sou, Y. S., Mizushima, T., Ezaki, J., Ueno, T., et al. (2008). Structural basis for sorting mechanism of p62 in selective autophagy. J. Biol. Chem. 283, 22847-22857. doi: 10.1074/jbc.M802182200

Ishigami, M., Hiraki, K., Umemura, K., Ogasawara, Y., Ishii, K., and Kimura, H. (2009). A source of hydrogen sulfide and a mechanism of its release in the brain. Antioxid. Redox Signal. 11, 205-214. doi: 10.1089/ARS.2008.2132

Kamat, P. K., Kalani, A., and Tyagi, N. (2015). Role of hydrogen sulfide in brain synaptic remodeling. Methods Enzymol. 555, 207-229. doi: 10.1016/bs.mie. 2014.11.025

Kim, B., Lee, J., Jang, J., Han, D., and Kim, K. H. (2011). Prediction on the seasonal behavior of hydrogen sulfide using a neural network model. ScientificWorldJournal 11, 992-1004. doi: 10.1100/tsw.2011.95

Kim, J. Y., and Bae, H. J. (2017). Spontaneous intracerebral hemorrhage: management. J. Stroke 19, 28-39. doi: 10.5853/jos.2016.01935
HW, CL, TW, and MZ interpreted the data for the work. MZ, $\mathrm{HS}, \mathrm{XC}$, and LT wrote the manuscript.

\section{FUNDING}

This work was supported by the National Natural Science Foundation of China (Nos. 81601306, 81301039, and 81530062), the China Post-doctoral Science Foundation Funded Project (No. 2015M570476), the Priority Academic Program Development of Jiangsu Higher Education Institutions (PAPD), the Jiangsu Talent Youth Medical Program (QNRC2016245), the Shanghai Key Lab of Forensic Medicine (KF1801), the Suzhou Science and Technology Development Project (SYS2018082), and the Fifth Batch of Gusu District Health Talent Training Project (GSWS2019060).

Li, L., Rose, P., and Moore, P. K. (2011). Hydrogen sulfide and cell signaling. Annu. Rev. Pharmacol. Toxicol. 51, 169-187. doi: 10.1146/annurev-pharmtox010510-100505

Lin, X., Ye, H., Siaw-Debrah, F., Pan, S., He, Z., Ni, H., et al. (2018). AC-YVADCMK inhibits pyroptosis and improves functional outcome after intracerebral hemorrhage. Biomed. Res. Int. 2018:3706047. doi: 10.1155/2018/3706047

Mannix, R. C., Zhang, J., Park, J., Zhang, X., Bilal, K., Walker, K., et al. (2011). Agedependent effect of apolipoprotein E4 on functional outcome after controlled cortical impact in mice. J. Cereb. Blood Flow Metab. 31, 351-361. doi: 10.1038/ jcbfm.2010.99

Olson, K. R., Healy, M. J., Qin, Z., Skovgaard, N., Vulesevic, B., Duff, D. W., et al. (2008). Hydrogen sulfide as an oxygen sensor in trout gill chemoreceptors. Am. J. Physiol. Regul. Integr. Comp. Physiol. 295, R669-R680. doi: 10.1152/ajpregu. 00807.2007

Park, J., Zhang, J., Qiu, J., Zhu, X., Degterev, A., Lo, E. H., et al. (2012). Combination therapy targeting Akt and mammalian target of rapamycin improves functional outcome after controlled cortical impact in mice. J. Cereb. Blood Flow Metab. 32, 330-340. doi: 10.1038/jcbfm.2011.131

Paul, B. D., and Snyder, S. H. (2018). Gasotransmitter hydrogen sulfide signaling in neuronal health and disease. Biochem. Pharmacol. 149, 101-109. doi: 10.1016/j. bcp.2017.11.019

Qureshi, A. I., Suri, M. F., Ostrow, P. T., Kim, S. H., Ali, Z., Shatla, A. A., et al. (2003). Apoptosis as a form of cell death in intracerebral hemorrhage. Neurosurgery 52, 1041-1047. discussion 1047-1048.

Rodriguez, C., Sobrino, T., Agulla, J., Bobo-Jimenez, V., Ramos-Araque, M. E., Duarte, J. J., et al. (2017). Neovascularization and functional recovery after intracerebral hemorrhage is conditioned by the Tp53 Arg72Pro singlenucleotide polymorphism. Cell Death Differ. 24, 144-154. doi: 10.1038/cdd. 2016.109

Salihu, A. T., Muthuraju, S., Idris, Z., Izaini Ghani, A. R., and Abdullah, J. M. (2016). Functional outcome after intracerebral haemorrhage - a review of the potential role of antiapoptotic agents. Rev. Neurosci. 27, 317-327. doi: 10.1515/ revneuro-2015-0046

Selim, M., and Norton, C. (2018). Perihematomal edema: implications for intracerebral hemorrhage research and therapeutic advances. J. Neurosci. Res. doi: 10.1002/jnr.24372 [Epub ahead of print].

Shen, X., Ma, L., Dong, W., Wu, Q., Gao, Y., Luo, C., et al. (2016). Autophagy regulates intracerebral hemorrhage induced neural damage via apoptosis and NF-kappaB pathway. Neurochem. Int. 96, 100-112. doi: 10.1016/j.neuint.2016. 03.004

Shohami, E., Novikov, M., and Mechoulam, R. (1993). A nonpsychotropic cannabinoid, HU-211, has cerebroprotective effects after closed head injury in the rat. J. Neurotrauma 10, 109-119. doi: 10.1089/neu.1993.10.109

Tovar-y-Romo, L. B., Penagos-Puig, A., and Ramirez-Jarquin, J. O. (2016). Endogenous recovery after brain damage: molecular mechanisms that balance neuronal life/death fate. J. Neurochem. 136, 13-27. doi: 10.1111/jnc.13362 
van Asch, C. J., Luitse, M. J., Rinkel, G. J., van der Tweel, I., Algra, A., and Klijn, C. J. (2010). Incidence, case fatality, and functional outcome of intracerebral haemorrhage over time, according to age, sex, and ethnic origin: a systematic review and meta-analysis. Lancet Neurol. 9, 167-176. doi: 10.1016/S14744422(09)70340-0

Wang, T., Huang, Y., Zhang, M., Wang, L., Wang, Y., Zhang, L., et al. (2013). [Gly14]-humanin offers neuroprotection through glycogen synthase kinase3beta inhibition in a mouse model of intracerebral hemorrhage. Behav. Brain Res. 247, 132-139. doi: 10.1016/j.bbr.2013.03.023

Whalen, M. J., Dalkara, T., You, Z., Qiu, J., Bermpohl, D., Mehta, N., et al. (2008). Acute plasmalemma permeability and protracted clearance of injured cells after controlled cortical impact in mice. J. Cereb. Blood Flow Metab. 28, 490-505. doi: $10.1038 /$ sj.jcbfm.9600544

Whiteman, M., Armstrong, J. S., Chu, S. H., Jia-Ling, S., Wong, B. S., Cheung, N. S., et al. (2004). The novel neuromodulator hydrogen sulfide: an endogenous peroxynitrite 'scavenger'? J. Neurochem. 90, 765-768. doi: 10.1111/j.1471-4159. 2004.02617.x

Zhang, J. Y., Ding, Y. P., Wang, Z., Kong, Y., Gao, R., and Chen, G. (2017). Hydrogen sulfide therapy in brain diseases: from bench to bedside. Med. Gas Res. 7, 113-119. doi: 10.4103/2045-9912.208517

Zhang, M., Shan, H., Chang, P., Ma, L., Chu, Y., Shen, X., et al. (2017). Upregulation of 3-MST relates to neuronal autophagy after traumatic brain injury in mice. Cell. Mol. Neurobiol. 37, 291-302. doi: 10.1007/s10571-016-0369-9

Zhang, M., Shan, H., Chang, P., Wang, T., Dong, W., Chen, X., et al. (2014). Hydrogen sulfide offers neuroprotection on traumatic brain injury in parallel with reduced apoptosis and autophagy in mice. PLoS One 9:e87241. doi: 10. 1371/journal.pone.0087241

Zhang, M., Shan, H., Wang, T., Liu, W., Wang, Y., Wang, L., et al. (2013). Dynamic change of hydrogen sulfide after traumatic brain injury and its effect in mice. Neurochem. Res. 38, 714-725. doi: 10.1007/s11064-013-0969-4
Zhao, H., Pan, P., Yang, Y., Ge, H., Chen, W., Qu, J., et al. (2017). Endogenous hydrogen sulphide attenuates NLRP3 inflammasome-mediated neuroinflammation by suppressing the P2X7 receptor after intracerebral haemorrhage in rats. J. Neuroinflammation 14:163. doi: 10.1186/s12974-0170940-4

Zhao, H., Qu, J., Li, Q., Cui, M., Wang, J., Zhang, K., et al. (2018). Taurine supplementation reduces neuroinflammation and protects against white matter injury after intracerebral hemorrhage in rats. Amino Acids 50, 439-451. doi: 10.1007/s00726-017-2529-8

Zhu, X., Tao, L., Tejima-Mandeville, E., Qiu, J., Park, J., Garber, K., et al. (2012). Plasmalemma permeability and necrotic cell death phenotypes after intracerebral hemorrhage in mice. Stroke 43, 524-531. doi: 10.1161/STROKEAHA.111.635672

Zille, M., Karuppagounder, S. S., Chen, Y., Gough, P. J., Bertin, J., Finger, J., et al. (2017). Neuronal death after hemorrhagic stroke in vitro and in vivo shares features of ferroptosis and necroptosis. Stroke 48, 1033-1043. doi: 10.1161/ STROKEAHA.116.015609

Conflict of Interest Statement: The authors declare that the research was conducted in the absence of any commercial or financial relationships that could be construed as a potential conflict of interest.

Copyright (c) 2019 Shan, Qiu, Chang, Chu, Gao, Wang, Chen, Luo, Wang, Chen, Zhang and Tao. This is an open-access article distributed under the terms of the Creative Commons Attribution License (CC BY). The use, distribution or reproduction in other forums is permitted, provided the original author(s) and the copyright owner(s) are credited and that the original publication in this journal is cited, in accordance with accepted academic practice. No use, distribution or reproduction is permitted which does not comply with these terms. 